\title{
Response of fish assemblages to hydromorphological restoration in central and northern European rivers
}

\author{
Stefan Schmutz $\cdot$ Pavel Jurajda $\cdot$ Simon Kaufmann $\cdot$ Armin W. Lorenz $•$ \\ Susanna Muhar $\cdot$ Amael Paillex $\cdot$ Michaela Poppe $\cdot$ Christian Wolter
}

Received: 18 December 2014/Revised: 26 May 2015/ Accepted: 31 May 2015/Published online: 25 July 2015

(C) The Author(s) 2015. This article is published with open access at Springerlink.com

\begin{abstract}
European rivers are highly degraded and restoration efforts are becoming more frequent. However, only few restoration projects have been rigorously evaluated so far. We investigated the response of fish assemblages to hydromorphological restoration measures including river widening, creation of instream structures, flow enhancement, remeandering and side-channel reconnection. We sampled 15 rivers with pairs of degraded and restored sites and calculated the effect sizes (i.e., restored-degraded) for species richness, species diversity, fish density and habitat traits. We analysed the following factors potentially affecting restoration success: (1) length
\end{abstract}

Electronic supplementary material The online version of this article (doi:10.1007/s10750-015-2354-6) contains supplementary material, which is available to authorized users.

Guest editors: Jochem Kail, Brendan G. McKie,

Piet F. M. Verdonschot \& Daniel Hering / Effects of hydromorphological river restoration

S. Schmutz $(\bowtie) \cdot$ S. Kaufmann $\cdot$ S. Muhar · M. Poppe Department of Water, Atmosphere and Environment, Institute of Hydrobiology and Aquatic Ecosystem Management, University of Natural Resources and Life Sciences, Max-Emanuel-Straße 17, 1180 Vienna, Austria e-mail: stefan.schmutz@boku.ac.at

P. Jurajda

Institute of Vertebrate Biology, Academy of Sciences of the Czech Republic, Rvetna 8, 60365 Brno, Czech

Republic of the restored river stretch, (2) time after restoration and (3) hydromorphological quality of restoration. While species diversity and density did not respond to restoration, proportion of small rheophilic fish increased and eurytopic decreased. Short-term ( $<3$ years) and long-term effects ( $>12$ years) of restoration measures have a stronger effect on fish assemblages than mid-term effects. Furthermore, the hydromorphological quality and the length of the restored section are relevant for the restoration effects on the fish community. Future restoration projects should focus on more dynamic, self-sustaining habitat improvements extending over several kilometres and should be coupled with other measures such as restoring the river continuity and species reintroductions.

Keywords Restoration success - Effect size · Rheophilic fish · Restoration monitoring · Hydromorphological quality $\cdot$ Restored section length

\footnotetext{
A. W. Lorenz

Faculty of Biology, Department of Aquatic Ecology, University of Duisburg-Essen, Universitätsstr. 5, 45141 Essen, Germany

A. Paillex

Eawag, Swiss Federal Institute of Aquatic Sciences and Technology, 6047 Kastanienbaum, Switzerland
} 


\section{Introduction}

In Europe, $64 \%$ of 1.17 million river kilometres have been reported not in good ecological status (EEA, 2012). Hydromorphological pressures and altered habitats have been identified as a significant pressure for 48.2 and $42.7 \%$ of the rivers, respectively (Fehér et al., 2012). Similarly, in the United States, $44 \%$ of 0.9 million river and stream kilometres have been reported as impaired (USEPA, 2009). Habitat alteration occurred in $23.2 \%$ of the impaired rivers and flow alteration in $9.7 \%$. Therefore, besides improving water quality, which is still a significant pressure in European rivers, hydromorphological river restoration has become a key objective in river basin management (Schinegger et al., 2012).

Biota respond to hydromorphological river restoration in a site or river-specific way (Jungwirth et al., 1995; Lamouroux et al., 2006; Muhar et al., 2007; Zitek et al., 2008; Schmutz et al., 2014). Fish has been identified as a key indicator to reflect biotic response to river restoration (Haase et al., 2012). While there are many river-specific restoration studies, only few studies have compared the response of restoration measures across multiple rivers (Haase et al., 2012; Lorenz \& Feld, 2012; Januschke et al., 2014). Most of the multi-river comparisons were limited to specific regions, thus failing to provide general conclusions for larger areas or different bioregions.

Restoration measures may affect only specific species, life stages or functional groups before the entire community reacts. However, specific metrics, e.g., juvenile fish, have rarely been investigated (Lorenz et al., 2013). Information about restoration performance is important to value the success of restoration project and also to guide future restoration programmes in Europe.

Beside direct response of fish assemblages to hydromorphological changes, it is likely that the length of the restored river stretch and the time after restoration would also have an effect on fish communities. There is evidence that the dimension of restoration measures plays a critical role in the effects on biota (Schmutz et al., 2014). Moreover, fish assemblages recover over periods of 10-20 years (Jones \& Schmitz, 2009). However, so far just few of the above-mentioned

C. Wolter

Leibniz-Institut für Gewässerökologie und

Binnenfischerei, Müggelseedamm 310, 12587 Berlin, Germany factors have been tested in the restoration context across a large range of restored rivers.

For European rivers, the Water Framework Directive (WFD) aims at achieving good ecological status in natural river systems or, respectively, good ecological potential in heavily modified water bodies. The challenge is to predict how the biota will respond to restoration and what management actions are best suited. However, here is a lack of empirical data on relevant geographical and long-term scales required for assessing restoration success (Hering et al., 2010).

This study was part of a larger approach to analyse the response of biota to hydromorphological restoration within the EU-project REFORM (Muhar et al. this special issue). In addition to the effects on fish, responses of habitat, macrophytes, benthic invertebrates, floodplain vegetation, ground beetles and stable isotopes were analysed in a common framework (Muhar et al. this special issue).

The objective of the study is to test if there is a consistent change in fish assemblages in response to hydromorphological restoration measures at multiple sites of European rivers. We compare assemblagebased metrics with functional metrics and test if the dimension of the restoration measure, its hydromorphological quality and the time passed since restoration affect restoration success.

\section{Methods}

Site selection

In total, 15 pairs of degraded and restored sites were selected in seven regions covering a latitudinal gradient from central to northern Europe (latitude range 46-65). The restoration sites are located in Austria (two restoration sites), Switzerland (2), Czech Republic (1), Germany (4), Denmark (2), Sweden (2) and Finland (2) and vary in terms of river type, altitude, slope and size (Fig. 1, Online Appendix 1 and 2). It was intended to cover a wide range of different restoration measures, i.e., river widening, creating instream structures, flow enhancement, remeandering and side-channel reconnection. Restoration sites were classified according to prevailing morphological restoration type, i.e., (1) "widening", (2) "remeandering" (3) "instream structures" or in cases of combined hydrological, morphological and/or continuity restoration as (4) "multiple 


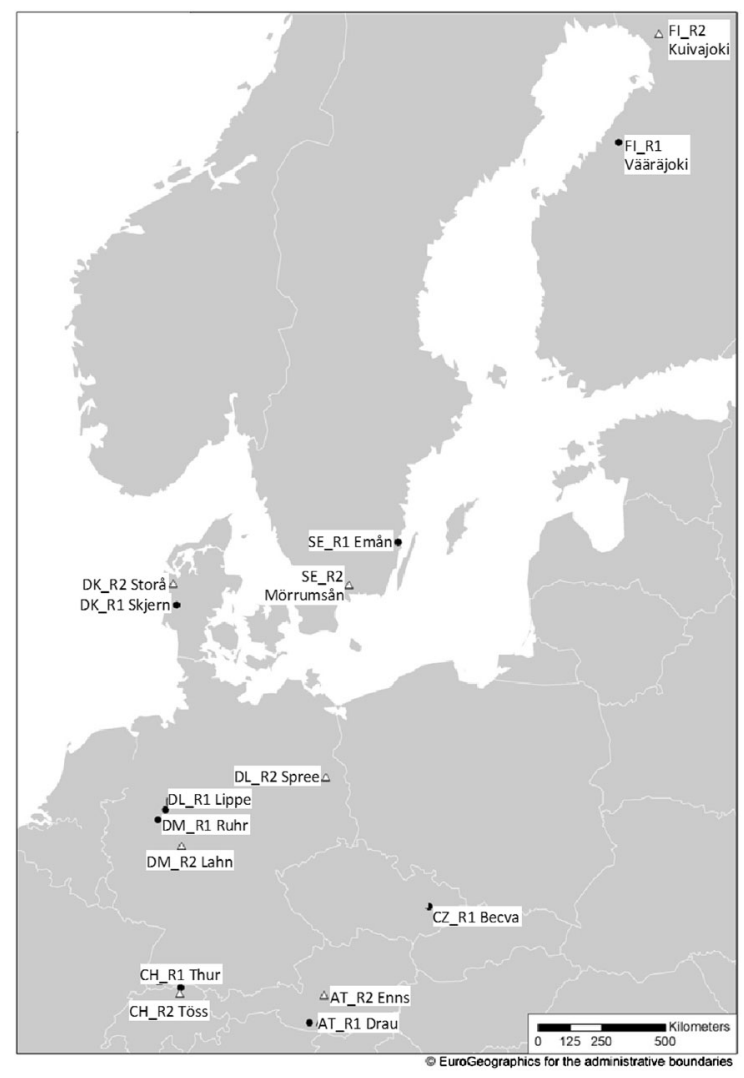

Fig. 1 Map with locations of restoration sites. Locations are coded with country names, restoration efforts $(R 1=$ large, $R 2=$ small, respectively, black dots and white triangles) and river names (e.g., AT_R1_Drau: Austria-large restoration River Drau)

restoration measures" (Online Appendix 1 and 2). One sample section (R1) was selected in the downstream part of each of the restored river sections and a second one in a degraded section (D1) directly upstream of the restored section. In each of the regions (except for the Czech Republic), a second restoration project was selected in a river of comparable size and character. In contrast to the R1-section, these restored sections were shorter and/or restoration has been performed with less intensity ("small restoration" vs. "large restoration"). Similarly to the large restoration, one study site was selected in the short restored section (R2) and one in a degraded section directly upstream (D2).

Fish sampling

Fish were sampled in each restored and each degraded section in the years 2011-2014 during summer or autumn. The sampling of fish followed standardised electric fishing procedures, as set out in the CEN directive "Water Analysis - Fishing with Electricity" (EN 14011). According to the CEN-standard, the main purpose of the standardised sampling procedure is to record information concerning fish composition and abundance. Electric fishing at a given site was conducted over a river length of 10-20 times the river width, with a minimum length of $100 \mathrm{~m}$. This was to ensure that the sampling covered the variability of habitats and fish communities within river sections and to guarantee representative characterisation of fish assemblages. However, in large and shallow rivers (width $>15 \mathrm{~m}$ and water depth $<70 \mathrm{~cm}$ ), several sampling areas with a cumulative total of at least $1,000 \mathrm{~m}^{2}$ were prospected by wading, covering all types of mesohabitats present at a given sampling site (partial sampling method). The length of the sampling site was again calculated as 10-20 times the river width. In large and deep rivers, fish were sampled with hand-held electrodes in the river margins and delimited areas of habitat, or using electric fishing boats with booms. We consider the potential effect of different sampling methods in small and large rivers as negligible because the focus of the analysis was dedicated to the pairwise comparison of degraded and restored sites, each pair of which was sampled in the same way. All fish collected were identified to species level by external morphological characteristics. The total number of specimens per species was recorded, and the total length of all fish captured was measured in order to discriminate between small $(\leq 15 \mathrm{~cm}$ body length) and large $(>15 \mathrm{~cm})$ fish and to compute metrics for different size classes.

\section{Attributes of fish assemblages}

The catch data were standardised by dividing the number of sampled fish by the sampled area (Ind ha ${ }^{-1}$ ). We calculated (1) the total number of species, (2) the proportional densities of species $\left(\mathrm{p}_{\mathrm{i}}\right)$ and (3) the total density per hectare for all species and habitat traits (rheophilic, limnophilic and eurytopic species). The proportional abundance of species and the fish densities were divided into small $(\leq 15 \mathrm{~cm})$ and large $(>15 \mathrm{~cm})$ fish. In total 13 metrics were considered in the analyses. We assigned all species to habitat traits according to the EFI+classification (EFI+Consortium, 2009) and discriminated between salmonid and non-salmonid and 
native and exotic species. We distinguished between salmonid and non-salmonid communities to analyse potential community shifts due to restoration, i.e., rhithralisation or potamalisation effects. In order to assess the potential influence of the sampling intensity on the number of species, we regressed the sampling area against the number of species. Furthermore, we calculated the Shannon-Wiener diversity index $H=-\sum\left(p_{\mathrm{i}}{ }^{*}\right.$ $\left.\ln \left(p_{\mathrm{i}}\right)\right)$. Relation among fish communities of different sites was analysed using multidimensional scaling (MDS). MDS takes a set of dissimilarities and returns a set of points such that the distances between the points are approximately equal to the dissimilarities. Euclidian distances were computed using relative species composition with the R@ function "dist". The R@ function "cmdscale" was used for the MDS. Results were plotted for the first two dimensions. Eigenvalues were computed as a measure for explained variation.

\section{Effect size and restoration success}

As sites vary in terms of species composition and abundance due to natural differences, we used effect size as a standardised metric for comparing pairs of degraded and restored sites. We calculated effect sizes as the values of restored sites minus the values of degraded sites (i.e., R-D). An effect size of zero indicates no change, a positive value represents an increase and a negative value represents a decrease. First, effect sizes were tested for being different to zero using Student's $t$ test and Bonferroni correction for multiple testing (i.e., significant $\mathrm{p}$ value after Bonferroni correction $p=0.05 / 13=0.00385)$. Second, highly correlated metrics (Pearson: $|r|>0.8$ ) were removed in an iterative way. Metrics with the highest number of correlations with other metrics were removed, and the procedure was repeated until only uncorrelated metrics remained. Significant non-redundant positive change was considered as a restoration success for species richness, densities and diversity except for eurytopic fish, where a decrease was an indicative for restoration success, as eurytopic species might be favoured under degraded conditions due to lower habitat requirements.

Factors affecting restoration success

We analysed the following factors potentially affecting restoration success: (1) length of the restored river stretch, (2) time since restoration and (3) hydromorphological quality of restoration. The length of the restored river stretch $(\mathrm{km})$ was measured as from the uppermost to the lowermost border of the restored river stretch. The time since restoration is the number of years passed since the finalisation of restoration measures. The hydromorphological quality of restoration was assessed using four types of attributes related to (1) channel geometry and flow characteristics (flow velocity and character), (2) riverbed (water depth, bed stabilisation, substrate), (3) water-land transition zone (river width, stabilisation, woody debris, bedload accumulation), (4) riparian zone (cross section, bank protection, vegetation) and floodplain vegetation (extent and type). Each attribute was classified from 1 (high status) to 5 (bad status) following the WFD principle of status classification. Finally, an overall hydromorphological index was calculated by first averaging all attributes of an attribute type, followed by averaging the four attribute types. For more details on hydromorphological monitoring methods see Poppe et al. (this special issue). Correlations among potential factors affecting restoration success were tested using Spearman's rank correlation.

We used classification and regression trees (CRT), a recursive partitioning method, to model fish metrics as a function of (1) length of the restored river stretch $(\mathrm{km})$, (2) time since restoration (years) and (3) hydromorphological quality of restoration (index). Only metrics that responded significantly to restoration were used for the tree models. CRT methods were available in the package rpart for R-library (R-project CRAN). The rpart algorithm follows the tree function of Breiman et al. (1984). Tree methods encompass several advantages: (1) nonparametric basis, (2) no implicit assumption of linearity, (3) simplicity of results for interpretation and (4) ability of predictive classification for new observations. Trees were first developed with single factors (restored length, hydromorphology, time) and second with all factors combined. All analyses were computed using $\mathrm{R}^{\circledR}$ version 3.1.1.

\section{Results}

A total of 43 species and 25,746 individuals were caught, encompassing 20 rheophilic species, 15 eurytopic and 8 limnophilic species (Online Appendix 3). 
Due to the low number and densities of limnophilic species in both degraded and restored sites, this trait was not considered in further analyses. Exotic species occurred only in three of the fifteen pairs of sites (Online Appendix 2). Only three exotic species were caught, in total 53 specimens (Carassius auratus $(n=2)$, Oncorhynchus mykiss $(n=37)$, Pseudorasbora parva $(n=14)$.

Regressing the number of species against the sampling area revealed a significant response $(F=11.08, p=0.003)$, but the result turned insignificant when removing the site with the highest number of species (DE_Lippe_R1, 21 species) $(F=0.8392$, $p=0.368$ ). As this relationship was triggered only by one site, it was not considered influential for the further analyses.

MDS revealed closer relationships within paired sites (degraded and restored) than among different locations (Fig. 2). Fifteen sites are dominated by nonsalmonid and fifteen by salmonid species. Eleven pairs remained in the same type of fish community after restoration. One pair changed from salmonid to nonsalmonid (CH_Thur_D1/CH_Thur_R1) and three from non-salmonid to salmonid communities (DK_Storaa_D2/DK_Storaa_DR, SE_Morrum_D2/ SE_Morrum_R2, SE_Eman_D1/SE_Eman_R1).

Restoration had a significant effect ( $t$ test, $p<0.05$ ) on five metrics out of 13 , with significant changes and no redundancy with other metrics (Table 1; Fig. 3). Mean species richness increased by approximately one species. The density of rheophilic fish and of small rheophilic fish and the proportion of density of small rheophilic fish increased. However, only the proportion of density of small rheophilic fish (increase of 24\%) was significant when considering the Bonferroni corrected $p$ value ( $t$ test, $p<0.00385$ ). Metrics related to eurytopic fish decreased or changed only slightly; however, they were either not significant or redundant to other metrics. Neither total density nor Shannon-Wiener diversity increased significantly. No difference between small and larger restoration measures was found when using the most significant metric, i.e., proportion of small rheophilic fish ( $t$ test, $p=0.8689$, Fig. 4).

The hydromorphological index of restored sites ranged from 1.4 to 2.5 (median 1.9), indicating "high" to "good" hydromorphological status; however, there was no significant difference between long and short restoration measures ( $t$ test, $p=0.0533$ ). Restored sites were monitored in years 2011-2014, 1-17 years (median 7 years) after completion of restoration measures, and the length of restoration measures covered a wide range between 0.2 and $26.0 \mathrm{~km}$ (median $0.9 \mathrm{~km}$ ). Correlations among potential factors affecting restoration success were low and not significant (Spearman's rank correlation $r<0.26, p>0.34$ ).

Based on single-factor regression tree analyses, using the only significant and non-redundant metric proportion of small rheophilic fish as an independent variable, sites with restoration lengths $>1.95 \mathrm{~km}$ revealed stronger responses to restoration than shorter stretches.
Fig. 2 Multidimensional scaling (MDS) of fish communities of degraded and restored sites. Sites are coded with country names and restoration efforts $(R 1=$ large, $R 2=$ small $)$ and respective control sites $(D 1, D 2)$. For river names see Fig. 1 and Online Appendix 1 and 2. Red italics non-salmoniddominated sites, Blue salmonid-dominated sites (including cumulative eigenvalues for the first two dimensions)

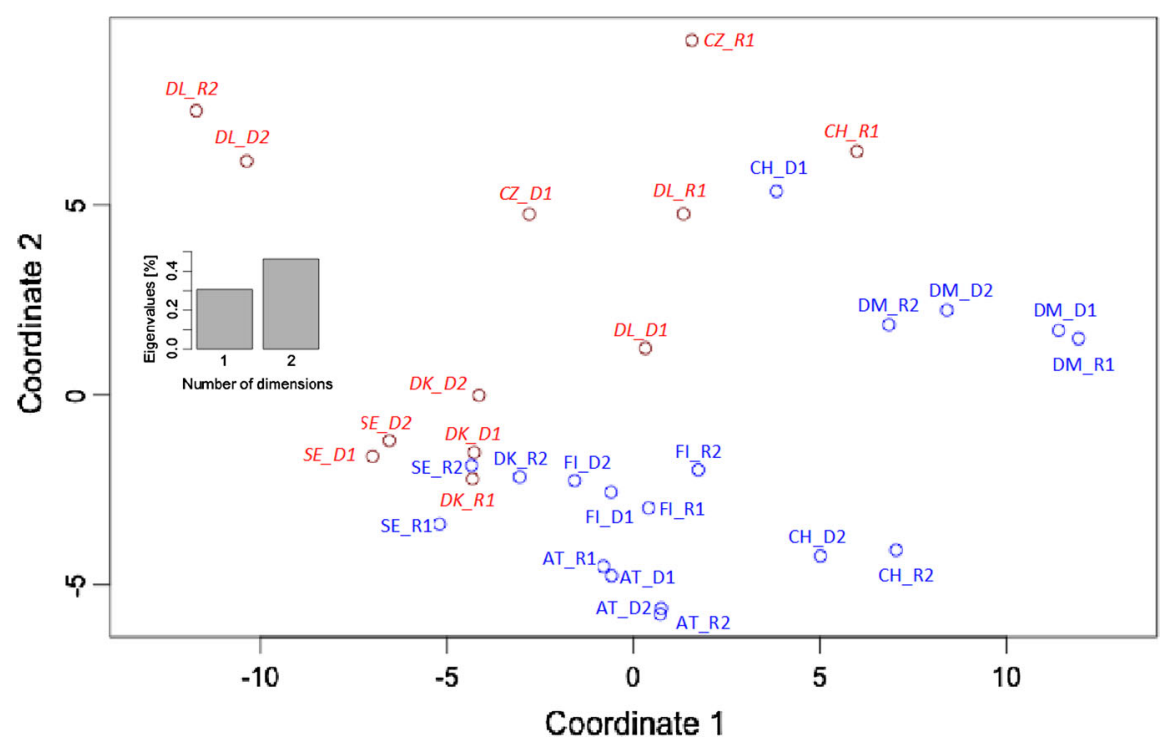


Table 1 Effect size measured for 13 fish metrics

\begin{tabular}{llrlr}
\hline Fish metric & Unit & Mean effect size & $p$ value & Redundancy \\
\hline Species richness & Number & 1.07 & 0.03310 & Not redundant \\
Richness rheophilic & Number & 1.00 & 0.02700 & Not redundant \\
Density rheophilic & Number per ha & 301.33 & 0.03660 & Not redundant \\
Density rheophilic small & Number per ha & 213.63 & 0.02080 & Not redundant \\
Proportion density rheophilic small & Percentage & $\mathbf{2 4 . 1 1}$ & $\mathbf{0 . 0 0 3 5 0}$ & Not redundant \\
Total density & Number per ha & 313.07 & 0.41690 & - \\
Shannon diversity & Index & 0.14 & 0.14190 & - \\
Richness eurytopic & Number & 0.00 & 0.97500 & - \\
Density eurytopic & Number per ha & -2.19 & 0.20610 & - \\
Density eurytopic small & Number per ha & -84.02 & 0.09380 & - \\
Proportion density rheophilic & Percentage & 19.88 & 0.01560 & Redundant \\
Proportion density eurytopic & Percentage & $-\mathbf{1 9 . 7 6}$ & $\mathbf{0 . 0 0 3 3 0}$ & Redundant \\
Proportion density eurytopic small & Percentage & $\mathbf{- 1 7 . 1 9}$ & $\mathbf{0 . 0 0 0 8 0}$ & Redundant \\
\hline
\end{tabular}

$T$ test $p$ values, significance level and redundancy (for significant metrics) are given for each fish metric. Bold metrics indicate significant metrics considering Bonferroni correction $(p$ value $<0.00385)$

This was driven by three restoration sites (DE_Lippe_R1, DK_Skjern_R1, SE_Morrum_R2). Sites with hydromorphological indices $<2.14$ showed higher effect sizes than those with indices $\geq 2.14$ (AT_Enns_R2, DE_Lahn_R2, DE_Ruhr_R1, DE_Spree_R2). Restoration sites that were monitored before 3 years or after 12.5 years (CZ_Becva_R1, DE_Lahn_R2, DE_Lippe_R1, DK_Storaa_R2, SE_Eman_R1, SE_Morrum_R2) showed stronger restoration effects than those monitored between 3 and 12.5 years. When considering all three factors simultaneously, short-term responses were most important for high effect sizes (DK_Storaa_R2, SE_Eman_R1, SE_Morrum_R2). In addition, time effects and hydromorphological index interacted in a way that, when excluding the short-term effects, sites with very high hydromorphological index (indices <1.57) responded more strongly (CZ_Becva_R1, DE_Lippe_R1, DK_Skjern_R1, FI_Kuiva_H_R2) than others (Fig. 5).

Different types of restoration measures did not reveal differences in the response of the proportion of small rheophilic fish, except for two restoration sites with multiple restoration measures (Fig. 6).

\section{Discussion}

The hydromorphology of lotic ecosystems is being increasingly modified worldwide by damming, fragmentation, flow regulation and channel modification. Serious threats to riverine biodiversity are suspected (Collen et al., 2014), yet available field data are few and rarely address the various taxonomic, functional and phylogenetic components of biodiversity (Feld et al., 2014). At the same time, public awareness has increased and political masterplans (e.g., WFD) try to counteract the ecological degradation. Particularly in Europe and the U.S., large numbers of river restoration measures are being realised (Bernhardt et al., 2005). Assessing the outcome of river restoration projects is vital for adaptive management, evaluating project efficiency, optimising future programmes and gaining public acceptance (Woolsey et al., 2007). Although the effectiveness of river restoration has been analysed for many years, clear and detailed results are scarce (Bernhardt et al., 2005). For example, despite locating 345 studies on effectiveness of stream rehabilitation by Roni et al. (2008), firm conclusions about restoration techniques were difficult to make first due to the limited information provided on physical habitat, water quality and biota and second due to the short duration and limited scope of most published evaluations. Therefore, more in-depth studies on river restoration are required to provide the scientific basis for effective restoration programmes in future.

Only few studies compared the response of restoration measures across multiple rivers (Haase et al., 

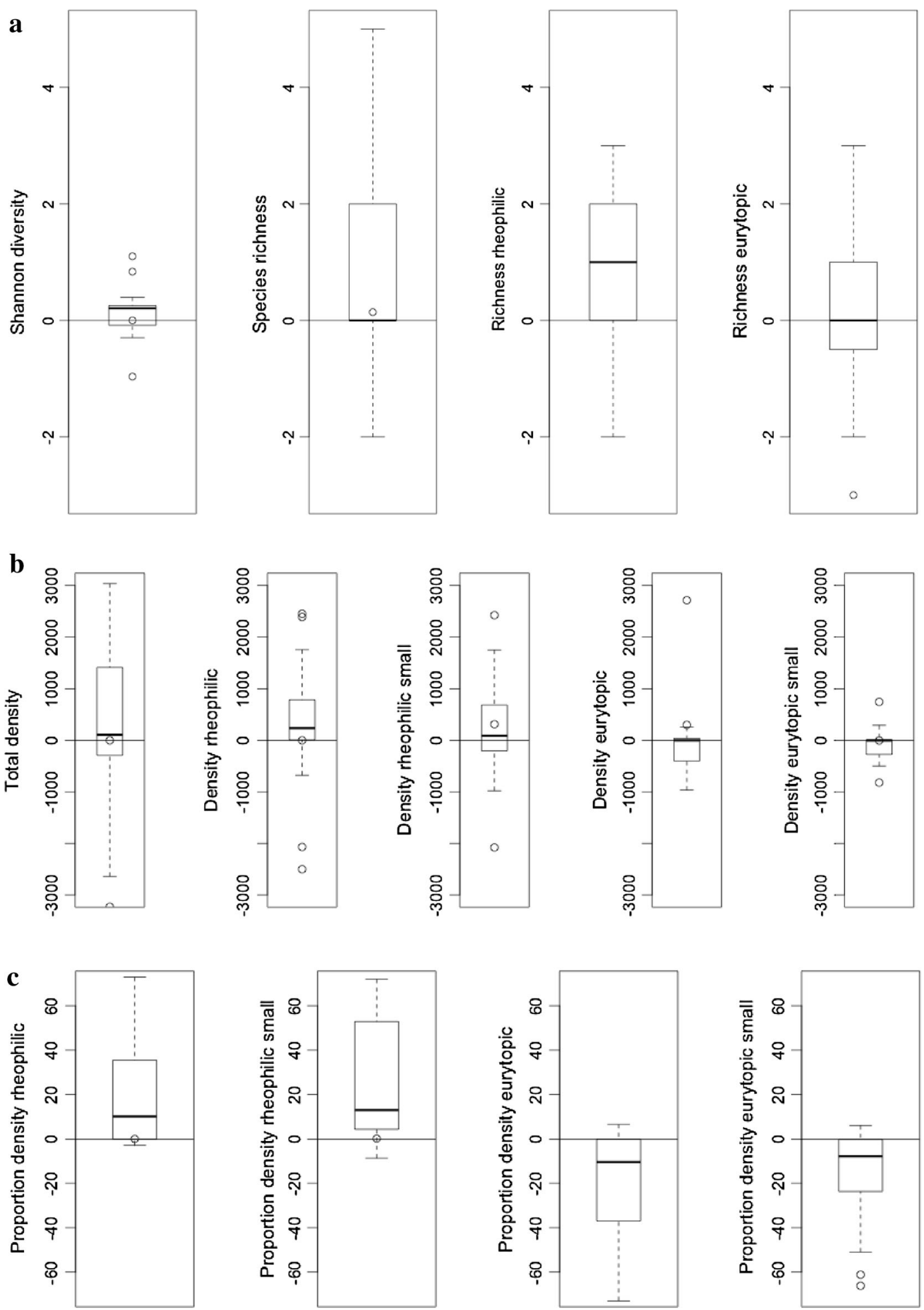

Fig. 3 Effect sizes of 13 analysed metrics related to a species richness and diversity, $\mathbf{b}$ density (Ind ha ${ }^{-1}$ ) and $\mathbf{c}$ proportion of density 

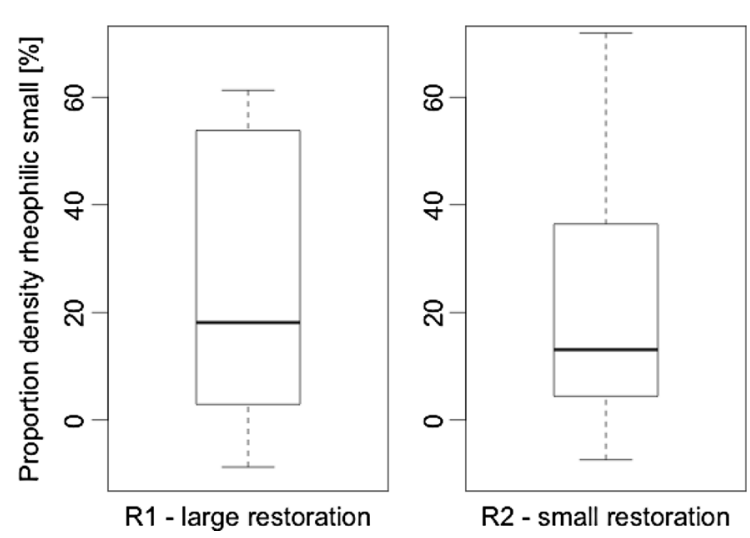

Fig. 4 Effect size of the proportion of small rheophilic fish in large $(R 1)$ and small $(R 2)$ restoration sites

2012; Lorenz \& Feld, 2012; Januschke et al., 2014). Most of the multi-river comparisons were limited to specific regions, preventing general conclusions for larger areas or different bioregions. For example, the study of Stoll et al. (2013) was restricted to lower mountain ranges of Germany and Schmutz et al. (2014) analysed the effect of restoration measures in the Austrian Danube.

In this study, fish data of 15 restoration sites covering a large latitudinal gradient from central to northern Europe were sampled and analysed. Species richness, species diversity and fish density showed only weak or no response to restoration, while habitat traits (guilds), i.e., rheophilic and eurytopic fish, reacted in a consistent way across the analysed restoration sites. Mean species richness increased by approximately one species under restored conditions, which can be attributed mainly to an increase of rheophilic species. Fish assemblages showed changes with hydromorphological restoration, while other biological groups in other studies revealed lessconsistent results indicating that stressors other than hydromorphological degradation might affect the biota in restored sections (Haase et al., 2012). Weak diversity responses to hydromorphological alteration were found for macroinvertebrates in lowland rivers (Feld et al., 2014). Their results suggested that taxonomic and trait replacement with hydromorphological alteration is not followed by changes in wholecommunity diversity. Morandi et al. (2014) analysed 37 restoration projects and found that in $76 \%$ community structure was the most often monitored metric, used more often than species richness (57\%).
Mueller et al. (2014) found that fish community composition only changed significantly in $50 \%$ of the restored rivers, depending on the occurrence of species sensitive to the structures introduced by the restoration treatments. A change in fish assemblage structure but not in biomass has also been detected in lake restoration (Gao et al., 2013).

These examples are consistent with our findings that restoration projects-as practised today-do not change species richness and diversity but rather community structure, in our case expressed as an increase of rheophilic and a decrease of eurytopic fish. One reason could be that in salmonid-dominated rivers species diversity is low even under natural conditions. However, in non-salmonid-dominated rivers other reasons are responsible, like water quality, presence of impassable barriers and poor colonization sources. Stoll et al. (2013) attributed weak restoration response to impoverished regional species pool as nearly all fish species occurring in restored reaches were present in reaches within a distance of $5 \mathrm{~km}$ up- or downstream of the restored reach. They concluded that the limited success in establishing natural fish assemblages in restored reaches was attributed to spatial limitation (e.g., due to fragmentation) and an impoverished regional species pools from which restored reaches recruit. Future restoration efforts and studies should also incorporate the effects of nearby barriers, temporal patterns in species dispersal, long-term and largescale processes, scale of restoration and minimum effective size of potential founder populations (Bond \& Lake, 2003; Lake et al., 2007; Radinger \& Wolter, 2014).

We found that the proportion of rheophilic fish increased after restoration. Similar change was also observed in the Danube after implementation of rehabilitation measures (Schmutz et al., 2014). Mueller et al. (2014) demonstrated that, besides lithophilic and invertivorous species, rheophilic fish benefit from restoration measures. In our study, small rheophilic fish showed a stronger reaction than all rheophilic fish. Likewise, Woolsey et al. (2007) proposed to use age structure besides guilds (species traits) as metrics for monitoring restoration success. Young of the year lithophilic fish-also strongly associated with riverine conditions-showed the highest increase in a similar study (Lorenz et al., 2013). As expected, the increase of rheophilic fish was accompanied by a decrease of eurytopic fish given the 


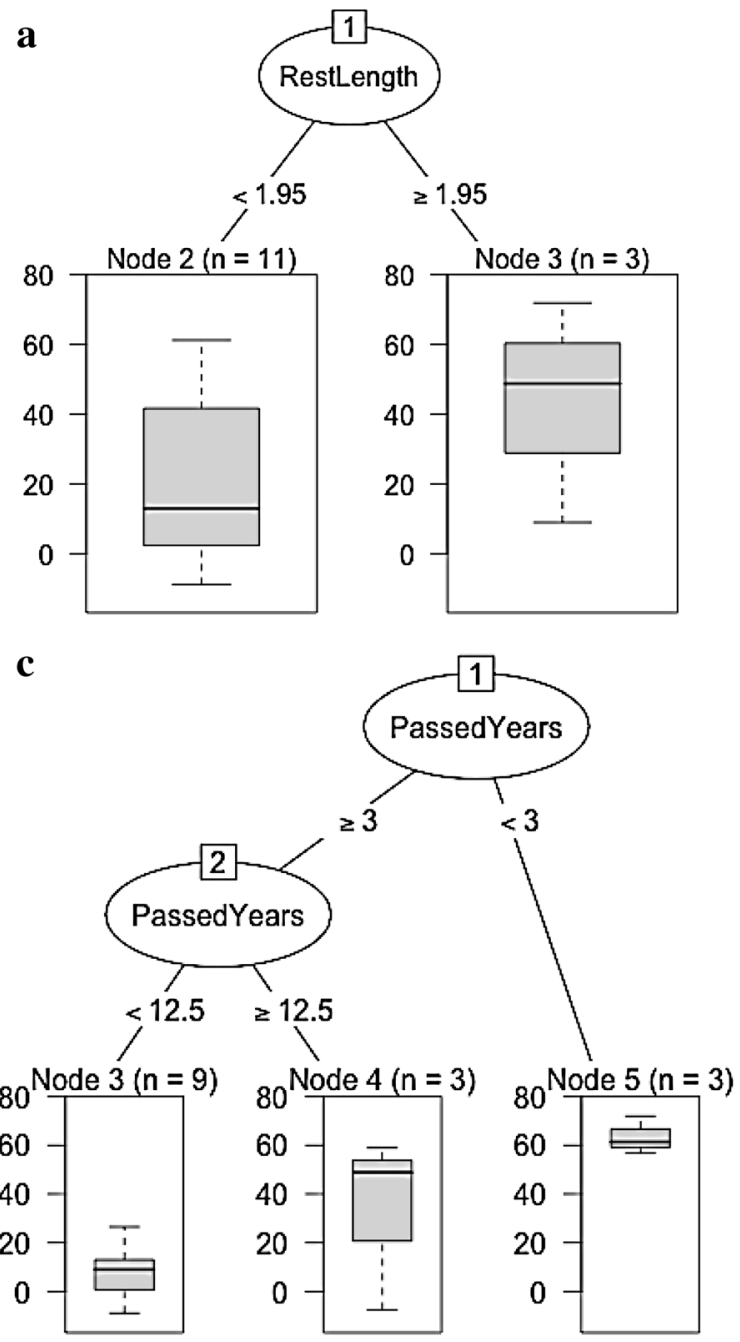

Fig. 5 Response of proportion of small rheophilic fish to a length of restoration measure ("RestLength", km), b hydromorphological index ("Hydromorphology", Index 1-5) and

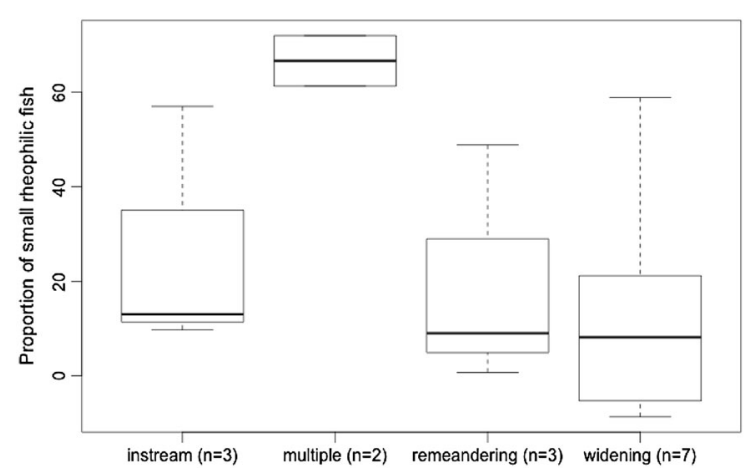

Fig. 6 Response of proportion of small rheophilic fish to different types of restoration measures
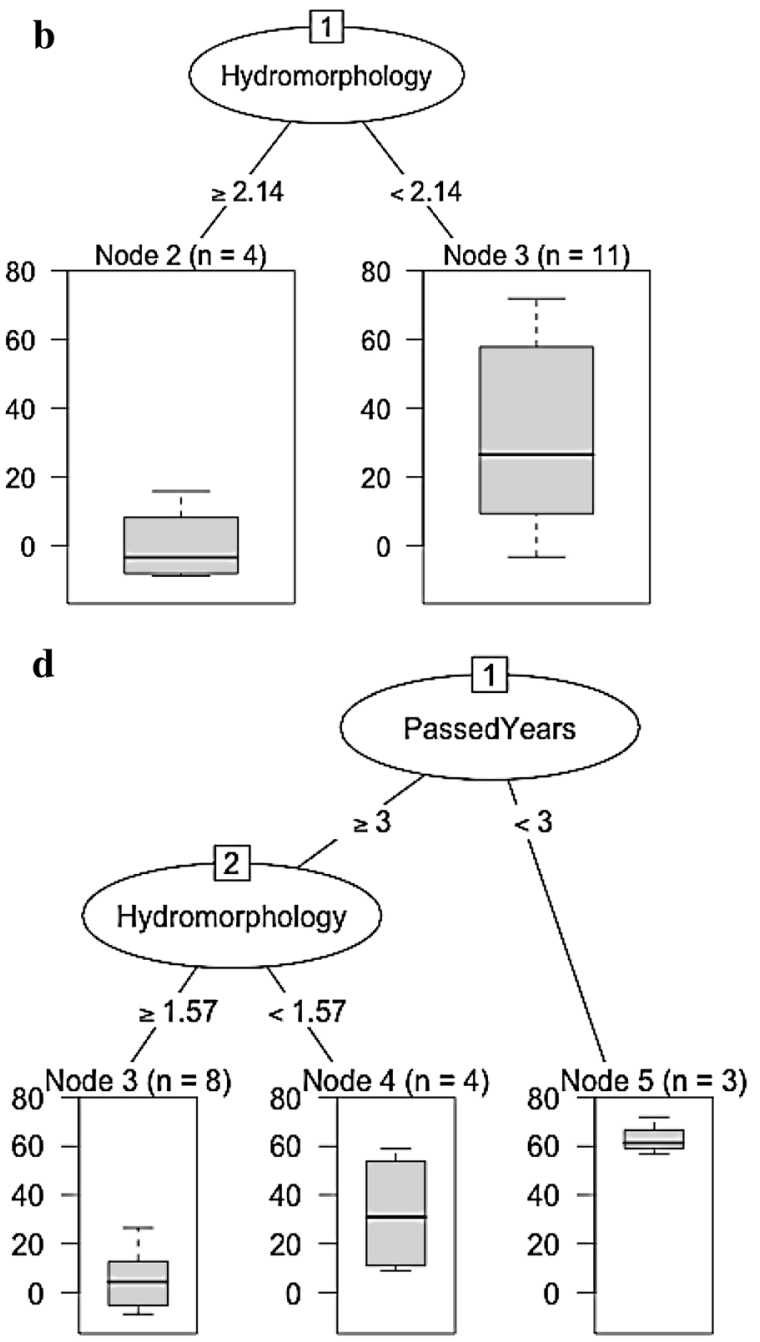

c number of years since restoration ("PassedYears"), using regression trees with single factors $(\mathbf{a}-\mathbf{c})$ or all factors combined (d)

fact that total density did not change as a result of restoration. Restoration measures applied in our study, i.e., river widening, creation of instream structures, flow enhancement, remeandering and side-channel reconnection, recreated micro- and mesohabitats important for rheophilic fish species particularly for early life history, i.e. ,gravel bars as spawning and nursery habitats.

There was no difference in the proportion of small rheophilic fish among restoration types, except for multiple restoration measures. However, only two sites with multiple restorations were analysed prohibiting general conclusions. Also Schmutz et al. 
(2014) found for the Danube that the type of restoration measure (instream habitat enhancement, backwater enhancement and extended enhancement including dynamic banks, side arms and oxbows) was less important than, for example, the length of the restored section.

Besides the importance of hydromorphological quality, our results showed that the response of fish was stronger within the first 3 and 12 years post restoration, and less pronounced in the mid-term range (3-12 years). This seems to contradict the expectation that longer recovery periods would result in stronger effects. Jones \& Schmitz (2009) reviewed 240 recovery studies across terrestrial and aquatic ecosystems and identified mean recovery times of 10-20 years for freshwater, brackish and marine systems. In our study, the median time frame between restoration and monitoring was 7 years, representing only one to three generations depending on fish species. Short recovery effects might be due to the creation of local gravel bars providing spawning and nursery habitats for rheophilic fish. This is in accordance with studies on artificial redd constructions. Pulg et al. (2013) found that in the first 2 years after artificial redd constructions, highly suitable spawning conditions were maintained, with a potential egg survival of more than $50 \%$ for brown trout (Salmo trutta). Afterwards, the sites offered moderate conditions, indicating an egg survival of less than 50\%. Conditions unsuitable for reproduction were expected to be reached five to 6 years after restoration. Otherwise, mid-term recovery might be hampered by the restricted spatial extent of restoration measures and lack of dynamic rejuvenation of created habitats. Finally, a mean increase of only one species in our restoration sites indicates that even longer recovery periods than 10 years might be necessary.

Muhar et al. (2007) showed a clear relationship between restoration effect and spatial extent of restoration measures, but even a re-establishment of $94 \%$ of aquatic habitats in the lateral dimension compared with reference conditions did not guarantee good fish ecological status sensu WFD since other factors limited recovery processes (limited longitudinal extent of restoration measures, continuity disruption). While in our study sites with restoration lengths over $1.95 \mathrm{~km}$ showed stronger responses, the highest positive restoration response in the Danube was observed for measures larger than $3.9 \mathrm{~km}$ (Schmutz et al., 2014). It seems that a minimum extent of restoration length is required to enable fish recovery, but thresholds might depend on river size, type of fish community and source populations in the surrounding (Stoll et al., 2013).

Exotic fish are considered to be a major threat to native fish communities in many parts of the world (Gozlan et al., 2010). Restoration may favour or impede exotic fish species (Jude \& DeBoe, 1996). In our study, only three exotic species occurred and densities were low making unlikely any potential negative impacts on restoration success.

The analyses cover different types of rivers, e.g., gravel-bed and sand-bed rivers, requiring different types of restorations, e.g., river widening or remeandering. Pooling together different types of rivers and restoration measures in combination with the limiting dataset impedes a detailed understanding of interactions between river types, restoration measures and recovery pathways. More detailed studies with higher number of sites are necessary to elucidate the specific roles of river types, restoration measures, created habitats, recovery time scales and spatial scales in restoration success.

\section{Conclusions}

Our study demonstrates that fish respond in a consistent way to hydromorphological restoration measures by an increase of rheophilic and a decrease of eurytopic fish. There seems to be a non-linear response to age of restoration with positive short- and long-term but less-pronounced mid-term effects. The restoration effect increases with habitat quality and length of restored river sections. However, current restoration practice and technique do not allow comprehensive recovery of lost species and population densities. The reasons for that are probably manifold: The length of current restoration measures is short (mostly $<1 \mathrm{~km}$ ) limiting the amount and diversity of provided habitats or the fulfilment of all demands of the life cycle, i.e., all life stages. The quality of habitat improvement has to receive more attention. Therefore, future restoration should focus on more dynamic, self-sustaining habitat improvements extending over several kilometres and should be coupled with other measures such as restoring the river continuity and species reintroductions. 
The further development of appropriate and selfsustaining restoration measures depends on improved knowledge on the effects of restoration. Measures have to address precisely the biophysical character of the rivers. Accordingly, the assessment of restoration effects across multiple river types in different bioregions has to be continued using larger datasets to better understand the effects of different restoration types.

Several factors are responsible for identifying restoration success and failure. In order to better cope with the multidimensional nature of restoration evaluations more comprehensive studies with larger datasets are necessary. Future monitoring programmes should be designed as long-term assessment to better document the process of habitat development and the reaction of biota over time as well as influences at a larger spatial scale (connectivity, population dynamics, etc.). The selection of response variables for measuring restoration success needs to be tailored to the regional characteristics of the rivers; in addition to frequently used parameters like species richness or diversity, more attention should be paid to attributes like and habitat guilds and population structure.

Acknowledgments We would like to thank E. Thaler for improving the English. This study was supported by the EUREFORM project, Restoring Rivers for Effective Catchment Management (Contract No. 282656) and the Austrian Science Fund, contract number P21735.

Open Access This article is distributed under the terms of the Creative Commons Attribution 4.0 International License (http:// creativecommons.org/licenses/by/4.0/), which permits unrestricted use, distribution, and reproduction in any medium, provided you give appropriate credit to the original author(s) and the source, provide a link to the Creative Commons license, and indicate if changes were made.

\section{References}

Bernhardt, E. S., M. A. Palmer, J. D. Allan, G. Alexander, K. Barnas, S. Brooks, J. Carr, S. Clayton, C. Dahm, D. Galat, S. Gloss, P. Goodwin, D. Hart, B. Hassett, R. Jenkinson, S. Katz, G. M. Kondolf, P. S. Lake, R. Lave, J. L. Meyer, T. K. O. Donnell, L. Pagano, B. Powell \& E. Sudduth, 2005. Synthesizing US river restoration efforts. Science 308: 636-637.

Bond, N. R. \& P. S. Lake, 2003. Local habitat restoration in streams: constraints on the effectiveness of restoration for stream biota. Ecological Management \& Restoration 4: 193-198.
Breiman, L., J. H. Friedman, R. A. Olshen \& C. J. Stone, 1984. Classification and Regression Trees. Wadsworth, Belmont, CA.

Collen, B., F. Whitton, E. E. Dyer, J. E. M. Baillie, N. Cumberlidge, W. R. T. Darwall, C. Pollock, N. I. Richman, A.M. Soulsby \& M. Böhm, 2014. Global patterns of freshwater species diversity, threat and endemism. Global Ecology and Biogeography 23: 40-51.

EEA, 2012. European Waters - Assessment of Status and Pressures. European Environmental Agency, Copenhagen.

EFI+Consortium, 2009. Manual for the application of the new European Fish Index - EFI+. Improvement and spatial extension of the European Fish Index., http://efi-plus.boku. ac.at/software/doc/EFI+Manual.pdf. Accessed 21 Dec 2014.

Fehér, J., J. Gáspár, K. Szurdiné-Veres, A. Kiss, P. Kristensen, M. Peterlin, L. Globevnik, T. Kirn, S. Semerádová, A. Künitzer, U. Stein, K. Austnes, C. Spiteri, T. Prins, E. Laukkonen \& A.-S. Heiskanen, 2012. Hydromorphological alterations and pressures in European rivers, lakes, transitional and coastal waters. Thematic assessment for EEA Water 2012 Report. Prague.

Feld, C. K., F. de Bello \& S. Dolédec, 2014. Biodiversity of traits and species both show weak responses to hydromorphological alteration in lowland river macroinvertebrates. Freshwater Biology 59: 233-248.

Gao, J., Z. Liu \& E. Jeppesen, 2013. Fish community assemblages changed but biomass remained similar after lake restoration by biomanipulation in a Chinese tropical eutrophic lake. Hydrobiologia 724: 127-140.

Gozlan, R. E., J. R. Britton, I. Cowx \& G. H. Copp, 2010. Current knowledge on non-native freshwater fish introductions. Journal of Fish Biology 76: 751-786.

Haase, P., D. Hering, S. C. Jähnig, A. W. Lorenz \& A. Sundermann, 2012. The impact of hydromorphological restoration on river ecological status: a comparison of fish, benthic invertebrates, and macrophytes. Hydrobiologia 704: 475-488.

Hering, D., A. Borja, J. Carstensen, L. Carvalho, M. Elliott, C. K. Feld, A.-S. Heiskanen, R. K. Johnson, J. Moe, D. Pont, A. L. Solheim \& W. Van de Bund, 2010. The European Water Framework Directive at the age of 10: a critical review of the achievements with recommendations for the future. The Science of the Total Environment 408: 4007-4019.

Januschke, K., S. C. Jähnig, A. W. Lorenz \& D. Hering, 2014. Mountain river restoration measures and their success(ion): effects on river morphology, local species pool, and functional composition of three organism groups. Ecological Indicators 38: 243-255.

Jones, H. \& O. Schmitz, 2009. Rapid recovery of damaged ecosystems. PloS one 4: 1-6.

Jude, D. J. \& S. F. DeBoe, 1996. Possible impact of gobies and other introduced species on habitat restoration efforts. Canadian Journal of Fisheries and Aquatic Sciences 53: 136-141.

Jungwirth, M., S. Muhar \& S. Schmutz, 1995. The effects of recreated instream and ecotone structures on the fish fauna of an epipotamal river. Hydrobiologia 303: 195-206.

Lake, P. S., N. Bond \& P. Reich, 2007. Linking ecological theory with stream restoration. Freshwater Biology 52: 597-615. 
Lamouroux, N., J.-M. Olivier, H. Capra, M. Zylberblat, A. Chandesris \& P. Roger, 2006. Fish community changes after minimum flow increase: testing quantitative predictions in the Rhone River at Pierre-Benite, France. Freshwater Biology 51: 1730-1743.

Lorenz, A. W. \& C. K. Feld, 2012. Upstream river morphology and riparian land use overrule local restoration effects on ecological status assessment. Hydrobiologia 704: 489-501.

Lorenz, A. W., S. Stoll, A. Sundermann \& P. Haase, 2013. Do adult and YOY fish benefit from river restoration measures? Ecological Engineering 61: 174-181.

Morandi, B., H. Piégay, N. Lamouroux \& L. Vaudor, 2014. How is success or failure in river restoration projects evaluated? Feedback from French restoration projects. Journal of Environmental Management 137: 178-188.

Mueller, M., J. Pander \& J. Geist, 2014. The ecological value of stream restoration measures: an evaluation on ecosystem and target species scales. Ecological Engineering 62: 129-139.

Muhar, S., M. Jungwirth, G. Unfer, C. Wiesner, M. Poppe, S. Schmutz, S. Hohensinner \& H. Habersack, 2007. Restoring riverine landscapes at the Drau River: successes and deficits in the context of ecological integrity. Developments in Earth Surface Processes 2025: 779-803.

Pulg, U., K. Sternecker, L. Trepl \& G. Unfer, 2013. Restoration of spawing habitats of brown trout (Salmo trutta) in a regulated chalk stream. River Research and Applications 29: 172-182.

Radinger, J. \& C. Wolter, 2014. Patterns and predictors of fish dispersal in rivers. Fish and Fisheries 15: 456-473.
Roni, P., K. Hanson \& T. Beechie, 2008. Global review of the physical and biological effectiveness of stream habitat rehabilitation techniques. North American Journal of Fisheries Management 28: 856-890.

Schinegger, R., C. Trautwein, A. Melcher \& S. Schmutz, 2012. Multiple human pressures and their spatial patterns in European running waters. Water and Environment Journal 26: 261-273.

Schmutz, S., H. Kremser, A. Melcher, M. Jungwirth, S. Muhar, H. Waidbacher \& G. Zauner, 2014. Ecological effects of rehabilitation measures at the Austrian Danube: a metaanalysis of fish assemblages. Hydrobiologia 729: 49-60.

Stoll, S., A. Sundermann, A. W. Lorenz, J. Kail \& P. Haase, 2013. Small and impoverished regional species pools constrain colonisation of restored river reaches by fishes. Freshwater Biology 58: 664-674.

USEPA, 2009. National Water Quality Inventory: Report to Congress. 2004 Reporting Cycle. Washington, DC 20460.

Woolsey, S., F. Capelli, T. Gonser, E. Hoehn, M. Hostmann, B. Junker, A. Paetzold, C. Roulier, S. Schweizer, S. D. Tiegs, K. Tockner, C. Weber \& A. Peter, 2007. A strategy to assess river restoration success. Freshwater Biology 52: 752-769.

Zitek, A., S. Schmutz \& M. Jungwirth, 2008. Assessing the efficiency of connectivity measures with regard to the EUWater Framework Directive in a Danube-tributary system. Hydrobiologia 609: 139-161. 